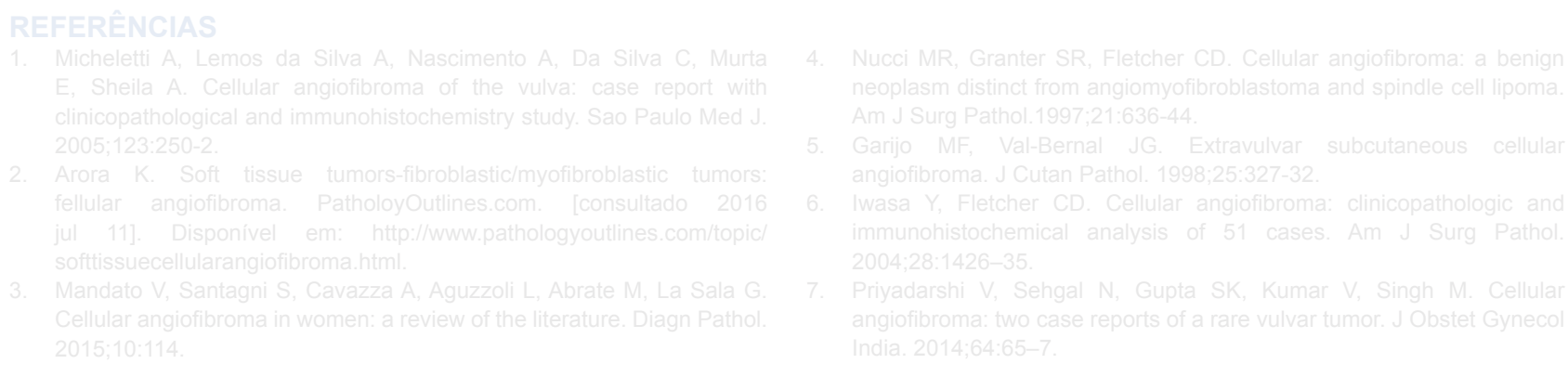

\title{
Mononucleose Infeciosa e Hepatite Colestática: Uma Associação Rara
}

\section{Infectious Mononucleosis and Cholestatic Hepatitis: A Rare Association}

\author{
Catarina SALGADO $\rrbracket^{1}$, Ana Margarida GARCIA ${ }^{2}$, Catarina RÚBIO ${ }^{3}$, Florbela CUNHA $^{3}$ \\ Acta Med Port 2017 Dec;30(12):886-888 - https://doi.org/10.20344/amp.8715
}

\begin{abstract}
RESUMO
A mononucleose infeciosa é uma das principais manifestações clínicas da infeção pelo vírus Epstein-Barr. Nesta síndrome, a elevação das aminotransferases é comum mas a colestase é rara, havendo poucos casos descritos na literatura. Adolescente, 14 anos, sexo feminino, admitida no serviço de urgência por febre, odinofagia e adenomegália cervical. Iniciou tratamento com amoxicilina e dois dias depois iniciou icterícia. A avaliação analítica foi compatível com hepatite colestática e a ecografia abdominal revelou hepatoesplenomegália, sem dilatação das vias bilares. O diagnóstico de infeção pelo vírus Epstein-Barr foi confirmado pela presença de marcadores serológicos. Este caso pretende alertar para uma manifestação rara de um agente infecioso comum e, consequentemente, para a inclusão da infeção aguda a vírus Epstein-Barr no diagnóstico diferencial de hepatite colestática na idade pediátrica.

Palavras-chave: Adolescente; Colestase; Hepatite; Infecções por Vírus Epstein-Barr; Mononucleose Infecciosa; Vírus Epstein-Barr
\end{abstract}

\section{ABSTRACT}

Infectious mononucleosis is one of the major clinical manifestations of Epstein-Barr virus infection. In this syndrome, elevation of liver transaminase levels is common but cholestasis is rare, with few cases described in the literature. We present the case of a 14-year-old female adolescent, admitted to the Emergency Room with fever, odynophagia and cervical adenomegaly. She was treated with amoxicillin and two days later he presented with jaundice. The analytical evaluation was compatible with cholestatic hepatitis and abdominal ultrasound revealed hepatosplenomegaly without dilatation of the bile ducts. The diagnosis of Epstein-Barr virus infection was confirmed by the presence of serological markers. This case aims to raise awareness of a rare manifestation of a common infectious agent and, consequently, to the inclusion of acute Epstein-Barr virus infection in the differential diagnosis of pediatric cholestatic hepatitis.

Keywords: Adolescent; Cholestasis; Epstein-Barr Virus Infections; Hepatitis; Infectious Mononucleosis

\section{INTRODUÇÃo}

A infeção pelo vírus Epstein-Barr (VEB) é muito comum, estimando-se que mais de $90 \%$ da população mundial tenha sido infetada. ${ }^{1}$

Nos países desenvolvidos, a primoinfeção ocorre habitualmente na adolescência ou nos adultos jovens. ${ }^{2} \mathrm{~A}$ gravidade da sintomatologia está relacionada com a resposta imunológica, sendo a infeção habitualmente subclínica durante a infância e francamente sintomática durante a adolescência. ${ }^{1,4-7}$ Neste grupo etário pode manifestar-se como mononucleose infeciosa (MNI) ${ }^{5,8}$ Inicialmente, existe um período prodrómico com astenia, anorexia e mialgias, e pode observar-se esplenomegália e/ou hepatomegália. ${ }^{5}$

O diagnóstico de MNI é presuntivo, baseado na associação clinico-laboratorial de sintomas típicos e linfócitos atípicos, podendo ser confirmado por testes serológicos. Estes dividem-se em testes inespecíficos: anticorpos heterófilos, e testes específicos, anticorpos contra antigénios do VEB. ${ }^{1,4} \mathrm{O}$ envolvimento hepático é frequente e traduz-se, habitualmente, pela elevação ligeira e autolimitada das aminotransferases. ${ }^{4,7} \mathrm{~A}$ colestase embora não rara nos adultos, está descrita esporadicamente na população pediátrica. $5,7,9$

\section{CASO CLÍNICO}

Adolescente, sexo feminino, 14 anos, previamente saudável, admitida no serviço de urgência (SU) de Pediatria por febre (com sete horas de intervalo de apirexia, temperatura de $38^{\circ} \mathrm{C}$ ) com três dias de evolução, associada a

1. Departamento de Pediatria. Hospital de Santa Maria. Centro Hospitalar Lisboa Norte. Lisboa. Portugal.

2. Departamento da Mulher, Criança e Adolescente. Centro Hospitalar Lisboa Central. Lisboa. Portugal.

3. Serviço de Pediatria. Hospital Vila Franca de Xira. Vila Franca de Xira. Portugal.

$\triangle$ Autor correspondente: Catarina Salgado. catarina.salgado@gmail.com

Recebido: 21 de janeiro de 2017 - Aceite: 26 de junho de 2017 | Copyright @ Ordem dos Médicos 2017 
odinofagia e adenomegália cervical unilateral. Estava sob terapêutica com ibuprofeno $400 \mathrm{mg}$ cada oito horas (5 mg/ $\mathrm{kg} / \mathrm{dose})$. Por hipótese diagnóstica de amigdalite estreptocócica foi medicada com amoxicilina na dose estabelecida de $50 \mathrm{mg} / \mathrm{kg} / \mathrm{dia}$. Dois dias depois, regressa por icterícia e exantema. Negava colúria, acolia, dor abdominal ou febre nas 48 horas prévias.

Do exame objetivo destacava-se o bom estado geral, icterícia da pele e escleróticas, exantema maculopapular, orofaringe com hiperémia amigdalina bilateral e adenomegália cervical dolorosa à direita. Não se evidenciou hepatoesplenomegália, dor abdominal à palpação ou Murphy vesicular.

Analiticamente, apresentava hemoglobina 13,6 g/ dL, leucócitos $22100 / \mu \mathrm{L}$, linfócitos 89,6\%, plaquetas 174

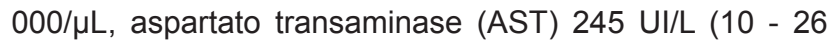
$\mathrm{UI} / \mathrm{L}$ ), alanina transaminase (ALT) $294 \mathrm{UI} / \mathrm{L}$ (19 - $44 \mathrm{UI} / \mathrm{L})$, Y-glutamil transpeptidase ( $\mathrm{Y}-\mathrm{GT}) 173 \mathrm{UI} / \mathrm{L}(10$ - $22 \mathrm{UI} / \mathrm{L})$, fosfatase alcalina $488 \mathrm{UI} / \mathrm{L}(103$ - $283 \mathrm{UI} / \mathrm{L})$, lactato desidrogenase (LDH) $872 \mathrm{UI} / \mathrm{L}(117-213 \mathrm{UI} / \mathrm{L})$, bilirrubina total/ direta 7,71/6,33 mg/dL (<1/0 - 0,3 mg/dL). A pesquisa de anticorpos heterófilos foi positiva. Exame sumário de urina sem pigmentos biliares. A ecografia abdominal mostrou moderada hepatoesplenomegália, sem dilatação da via biliar ou sinais de colecistite. As serologias para o VEB revelaram: viral capsid antigen (VCA) IgM e IgG positivos; early antigen (EA) e Epstein-Barr nuclear antigen (EBNA) negativos, com diagnóstico agudo de infeção a VEB. Não foram efetuadas outras serologias. Foram indicadas medidas sintomáticas e evicção escolar. A evolução foi favorável, com recuperação clínica completa e remissão analítica seis semanas após a apresentação inicial. O diagnóstico foi confirmado pela seroconversão (EBNA positivo, diminuição de IgM VCA e aumento de IgG VCA).

\section{DISCUSSÃO}

O VEB é um agente infecioso muito comum na população pediátrica, afetando por ano cerca de 345 - 671/100 000 adolescentes. ${ }^{7}$ A manifestação clínica clássica neste grupo etário é a $\mathrm{MNI},{ }^{3,6,8,10}$ podendo surgir com outros sinais e sintomas como esplenomegália (> 50\%), hepatomegália $(30 \%-50 \%)$ e exantema $(5 \%, 90 \%-100 \%$ nos casos tratados com ampicilina). ${ }^{2} \mathrm{~A}$ icterícia, por sua vez, é uma manifestação rara da infeção a VEB, estando descrita em menos de $5 \%$ dos doentes em idade pediátrica. ${ }^{6-7} \dot{E}$ mais frequente em pessoas com mais de 35 anos e a sua etiologia pode ser anemia hemolítica autoimune ou colestase, resultante de colecistite acalculosa, obstrução da via biliar por adenopatias ou hepatite colestática. ${ }^{7}$

No caso descrito, figurou um quadro clínico típico de MNI com surgimento de exantema após tratamento com amoxicilina e icterícia. Os exames laboratoriais confirmaram hiperbilirrubinémia direta na ausência de anemia, pelo que a hipótese de anemia hemolítica auto-imune seria improvável. A ecografia abdominal, por outro lado, revelou hepatoesplenomegália, achado frequentemente descrito na literatura, ${ }^{5,6,10} \mathrm{com}$ vias biliares não dilatadas e vesícula sem sinais de colecistite, excluindo, deste modo, uma causa de colestase extra-hepática.

O envolvimento hepático ligeiro é frequente $(90 \%$ dos doentes têm elevação das aminotransferases inferior a três vezes o limite superior), geralmente assintomático e autolimitado, ocorrendo principalmente na segunda semana de doença e resolvendo totalmente em duas a seis semanas. ${ }^{6,8,10}$ A lesão hepática grave é rara, mas quando ocorre é a principal causa de morte dos doentes com infeção aguda a VEB. ${ }^{10} \mathrm{~A}$ hepatite colestática, em contrapartida, caracterizada por hiperbilirrubinémia direta e elevação da fosfatase alcalina e $\mathrm{y}$-GT, não é comum. ${ }^{6}$ Nestes casos, o nível de aminotransferases é significativamente superior em comparação com o grupo que não apresenta colestase, estando descrito valores sete vezes acima do limite superior, achado este que pode incitar investigação etiológica adicional desnecessária. ${ }^{6}$

No presente caso, a hiperbilirrubinémia predominantemente direta (82\%) associada a elevações significativas da $\mathrm{Y}-\mathrm{GT}$, da AST e da ALT, traduzem lesão hepática mista, compatível com hepatite colestática. O mecanismo da hepatite colestática ainda permanece desconhecido, tendo sido sugeridas várias alternativas tais como: dano oxidativo; infeção direta dos linfócitos pelo vírus no epitélio biliar; diminuição da atividade dos sistemas de transporte sinusoidal e canalicular induzida por citocinas e disfunção dos organelos dos hepatócitos. 4,5,6,11 Ao contrário de outros vírus hepatotrópicos, não existe necrose hepatocelular nas biópsias hepáticas de doentes com hepatite colestática associada a VEB. Os achados histológicos incluem edema, vacuolização dos hepatócitos e infiltração periportal de monócitos. ${ }^{6}$

A maioria dos doentes com hepatite colestática associada a VEB recupera espontaneamente com terapêutica de suporte, não estando associado quadro de fadiga ou astenia crónica. A terapêutica antiviral e a corticoterapia não são eficazes e o seu uso é controverso. ${ }^{8}$

A doente que relatamos apresentava clinica típica de MNI (incluindo o exantema após amoxicilina) com icterícia, associada a serologias que confirmavam infeção aguda e confirmada a seroconversão posteriormente. Neste contexto, a hepatite colestática secundária a VEB surge como a hipótese diagnóstica mais provável, pelo que não foram efetuados outros estudos. Na maioria dos casos descritos a hepatite colestática pode ocorrer sem sintomas típicos de MNI, dificultando o diagnóstico que pode ser sugerido pela linfocitose e/ou esplenomegália. ${ }^{12}$

A toxicidade por fármacos é responsável por $10 \%$ das hepatites agudas e o quadro clínico é semelhante a uma hepatite vírica. ${ }^{1,4} \mathrm{O}$ ibuprofeno pertence à classe dos anti-inflamatórios não esteroides (AINEs), um dos grupos implicados com maior frequência na toxicidade hepática, podendo produzir necroinflamação e colestase por hipersensibilidade. Contudo, no caso apresentado, o diagnóstico de infeção aguda por VEB com boa evolução clinico-laboratorial, a ausência de relação temporal com a administração de ibuprofeno e a dosagem correta colocam a toxicidade por 
este fármaco como hipótese remota. Quando existe dúvida no diagnóstico pode efetuar-se biópsia hepática. ${ }^{4}$

Em conclusão, o presente caso pretende alertar para uma manifestação rara de um agente infecioso comum, o VEB. Deste modo, a infeção a VEB deve ser considerada no diagnóstico diferencial de icterícia e hepatite colestática em todas as idades, mesmo na ausência de sinais clínicos clássicos de MNI, por forma a evitar atitudes diagnósticas e terapêuticas desnecessárias. . $^{3,5,6}$

\section{REFERÊNCIAS}

1. Moreira E, Machado A, Machado L, Xavier C, Monteiro C, Cunha J, et al. Infecção pelo vírus Epstein-Barr e hepatite. Nascer Crescer. 2011; 20:73-5.

2. Agergaard J, Larsen CS. Acute acalculous cholecystitis in a patient with primary Epstein-Barr virus infection: a case report and literature review. Int J Infect Dis. 2015;35:67-72.

3. Al-Refaee F, Al-Enezi S, Hoque E, Albadrawi A. A case report of pediatric Epstein Barr virus (EBV) related cholestasis from Al-Adan Hospital, Kuwait. Open J Pediatr. 2015;5:23-6.

4. Barreales M, Pérez-Carreras M, Meizoso T, Garrido M, Masedo A, Colina F, et al. Epstein- Barr virus infection and cholestatic hepatitis. An Med Interna. 2006;23:483-6.

5. Demirdal T, Dermirtuk N. A rare presentation on EBV hepatitis. Eur $J$ Gen Med. 2007;4:33-5.

6. Shkalim-Zemer V, Shahar-Nissan K, Ashkenazi-Hoffnung L, Amir J, Bilavsky E. Cholestatic hepatitis induced by Epstein-Barr Virus in a
CONFIDENCIALIDADE DOS DADOS

Foi devidamente obtido o consentimento informado do doente.

\section{CONFLITOS DE INTERESSE}

Os autores declaram não terem qualquer conflito de interesse relativamente ao presente artigo.

\section{FONTES DE FINANCIAMENTO}

Os autores declaram não ter recebido subsídios ou bolsas para a elaboração do artigo.

\section{Pediatric Population. Clin Pediatr. 2015;1-5}

7. Salva I, Silva I, Cunha F. Epstein-Barr virus-associated cholestatic hepatitis. BMJ Case Rep. 2013;10.1136:1-2.

8. Yang SI, Geong JH, Kim JY. Clinical characteristics of Primary Epstein Barr Virus Hepatitis wit elevation of alkaline phosphatase and y-Glutamyltransferase in Children. Yonsei Med J. 2014;55:107-12.

9. Shaukat A, Tsai $H$, Rutherford R, Ananja FA. Epstein-Barr virus induced hepatitis: An important cause of cholestasis. Hepatol Res. 2005;33:24-6.

10. Crum NF. Epstein Barr virus hepatitis: case series and review. South Med J. 2006;99:544-7.

11. Kimura H, Nagasaka T, Hoshino $Y$, Hayashi N, Tanaka N, Xu JL, et al. Severe hepatitis caused by Epstein Barr virus without infection of hepatocytes. Hum Pathol. 2001;32:757-62.

12. Vine LJ, Shepherd K, Hunter JG, Madden R, Thornton C, Ellis V, et al. Characteristics of Epstein-Barr virus hepatitis among patients with jaundice or acute hepatitis. Aliment Pharmacol Ther. 2012;36:16-21. 